\title{
Twin Cities-A Matter of Identity and Belonging
}

\author{
Nitza Davidovitch and Heli Arbili \\ Ariel University
}

\begin{abstract}
The term "twin cities" refers to a program in which cities from different places in the world form a "twinning" alliance that serves as a setting for educational, cultural, political, and social collaborations (Grosspietsch 2009). The purpose of the program is to promote the twin cities in all aspects of life (Jayne, Hubbard, and Bell 2013) and facilitate a feeling of belonging and identity among their residents (Ogawa 2012). In the current study, the cities of Beer Sheva and Nahariya were taken as case studies for examining the contribution of the program to promoting residents' feeling of belonging to their Jewish identity. Specifically, the current study attempted to examine the effect of town of residence and age group on feeling of belonging, and whether familiarity with the Twin Cities program affected the feeling of belonging to Jewish identity, in the assumption that residents familiar with the program would report a stronger feeling of belonging than residents not familiar with it. The study included 147 participants aged 17-64, of them 80 residents of Beer Sheva and 67 of Nahariya. All the participants were recruited to the study voluntarily and were requested to complete an online self-report questionnaire examining feeling of belonging to Jewish identity. Moreover, an interview was conducted with the representative of the delegations at the Amal school in Nahariya, to reaffirm the findings. The research findings refuted the main research assumption that the Twin Cities program would influence the feeling of belonging. In fact, the current study indicates that no correlation was found between feeling of belonging and any of the research measures, aside from religiosity. Furthermore, and in contrast to the hypothesis, the research findings indicate that participants who were not familiar with the program reported a stronger feeling of belonging than participants who were familiar with it. Due to the surprising findings, the current study raises the possibility that the Twin Cities program is undergoing a process of change and thus promotes individual values more than collective values. This contention changes the essential purpose of the program and this is the significance of the current study.
\end{abstract}

Keywords: twin cities, identity, belonging, values, Israel

\section{Literature Review}

The current study deals with the Twin Cities program, where cities in different countries form a twinning alliance and maintain collaborations in economic, social, cultural, and other domains. The basic premise of this study is that the Twin Cities program strengthens, among other things, residents' feeling of belonging to the town and to their Jewish identity.

Nitza Davidovitch, Prof., Department of Social Studies, Ariel University, Israel; main research fields: Studies on Higher Education, Promotion of Academic Instruction, and Performance Measures in Higher Education, Development of Unique Assessment Studies, and Research Resource Development.

Heli Arbili, M.A., Department of Social Studies, Ariel University, Israel; main research fields: Moral Education. 


\section{Twin Cities-Definition and Purposes}

The term twin cities refers to an association whereby geographically and politically distinct cities form a twinning alliance in which they maintain educational, cultural, and economic collaborations (Grosspietsch 2009). The motives of a certain town for forming an affiliation with another town within the Twin Cities program are many and varied and they usually include a previous relationship between the mayors, commercial relations between the two countries, historical relationships, communities of immigrants, common geographical challenges, collaborations related to fields of knowledge and marital relations, and more (Cremer, De Bruin, and Dupuis 2001). Therefore, when one or more of the motives exists, the mayors conduct lengthy negotiations, ending with a memorandum of understanding that defines the relationship between the two cities as that of twin cities (http://www.sister-cities.org/about-sister-cities-international).

Often, the relationship formed between two local authorities is a mutual relationship that constitutes a setting for many programs such as student exchanges, joint projects, and designated journeys (Grosspietsch 2009). Of the diverse collaborations and activities conducted in the twin cities context, some notable examples are exchanges of artwork among students, educational panels, student exchanges, online exchanges of letters between residents of twin cities, social visits by representatives of twin cities, reciprocal visits by mayors, cultural festivals and celebrations that take place at both cities simultaneously, and knowledge exchanges on commercial, technological, and scientific issues (Cremer, De Bruin, and Dupuis 2001).

For example, in the city of Manchester in the US, which has sister agreements with several countries including Israel, political visits and academic tours are held regularly between the city's representatives and those of the sister city. These tours provide the city's representatives with economic, cultural, and political knowledge that they utilize in their respective jurisdictions, and through which they acquire strategies to advance their city (Jayne, Hubbard, and Bell 2013).

Moreover, the Twin Cities program has many goals, beginning from economic and cultural advancement, through strengthening historical ties, to empowering the residents' feelings of belonging. The Twin Cities program aims to promote the two allied communities that develop a reciprocal relationship based on intimacy and trust, reinforcing the historical and cultural bonds between the two communities (Jayne, Hubbard, and Bell 2013). In addition, the Twin Cities program intends to strengthen the political and economic interests of the countries' leaders, with the purpose of maintaining the principle of globalization and integrating between economies, cultures, and communities all over the world (Jayne, Hubbard, and Bell 2013). In this way, the Twin Cities program promotes the culture, industry, economy, and education of the two countries and further enhances their bonds (Jayne, Hubbard, and Bell 2013).

Further, the research literature indicates that one of the major goals of the Twin Cities program is to strengthen residents' sense of collective identity and their feeling of belonging to their town of residence, faith, and cultural origins. Enhancing the feeling of belonging is an outcome of the diverse collaborations between the cities, through which the citizens of one country bond with those of another who share the same faith and/or culture (Ogawa 2012). This goal underlies the current study.

\section{Twin Cities-History and Situation in Israel}

Historically, the Twin Cities program began to evolve in Europe, after World War II, with the purpose of connecting between Europeans and creating a better future based on peace and on mutual ties both between the 
various authorities and applied to the entire population. Indeed, the first alliance formed was created in 1947 between Britain and Germany, and served as a basis for politicians' foreign travels and student exchange initiatives. This alliance was followed by other alliances between countries, with the number of cities reaching such agreements climaxing in the late 1980s (Grosspietsch 2009).

While the program grew in Europe, it began to expand elsewhere as well, and its characteristics and the activities it encompassed became more flexible (Grosspietsch 2009). For example, in light of the program's expansion in the United States, President Eisenhower established the Twin Cities program in 1956, which in time became an independent civil non-profit organization aimed at strengthening ties between different communities in the world. The Twin Cities organization aims to increase international cooperation on the municipal level, to promote global peace, to act in favor of forming cultural and political ties, and to arrange for economic development (from the Sister Cities website at: http://www.sister-cities.org/about-sister-cities-international). Indeed, in recent years the Twin Cities program has been serving as a significant economic lever for cities participating in the program. For example, the alliance formed between Kumamoto, Japan, and San Antonio, Texas, encouraged economic investment in the US by 30 Japanese companies, significantly promoting the local economy (Ballantine 2013).

The reason for allying with a certain city differs. Some programs aim to strengthen bonds between countries, as in the relationships between German cities and cities in other countries, including the United States, Russia, and Israel (Panka 2015), while others are intended to promote the allied cities from an economic, cultural, or educational aspect (from the Sister Cities website at: http://www.sister-cities.org/about-sister-cities-international).

In the specific case of Israel, hundreds of alliances have been formed between local authorities and cities throughout the world, aimed at promoting concrete goals in the domains of commerce, economy, the environment, tourism, science, culture, and so on, leading to development of the city and actual benefits for its residents (from the website of the Federation of Local Authorities in Israel: http://www.masham.org.il/?CategoryID=221\&ArticleID=94). Israel's first alliance with the world, within the Twin Cities program, was with Germany beginning from 1965, when the two countries established diplomatic relations (Reinstein 2012). Since then, Germany and Israel have formed some 100 twinnings, and Israel has another approximately 400 alliances with other countries around the world, including South America, Canada, China, France, Russia, and more (from the website of the Federation of Local Authorities in Israel: http://www.masham.org.i1/?CategoryID=221\&ArticleID=94).

At present, according to data provided by the Federation of Local Authorities in Israel, the city of Tel Aviv has 26 twin cities, Haifa has 23, Eilat and Netanya-15, Rishon LeZion-13, Ashkelon, Nahariya, and Beer Sheva - 12, Ashdod, Petach Tikva, and Herzliya - 11, Tiberias - 10, Upper Nazareth - 9, Hadera, Raanana, and Ramle-8, and Jerusalem-3 (from the website of the Federation of Local Authorities in Israel: http://www.masham.org.il/?CategoryID=221\&ArticleID=94).

Of all Israeli cities collaborating with other cities around the world within the Twin Cities program, the current study will focus on the collaborations maintained by the cities of Nahariya and Beer Sheva. The choice of these cities as a case study, from which we will derive research conclusions, is based on the fact that these are two geographically distinct cities and that each of them has mutual relations with the same number of twin cities: 12 in Nahariya and 12 in Beer Sheva. 
In more detail, Nahariya has mutual relations with 12 cities around the world, four of them in Germany and the rest in the Czech Republic, France, Hungary, Greece, and the US. The first alliances formed by the city were with cities in Germany, when residents originating from these cities asked the mayor to form cultural ties with the communities to which they had belonged in their countries of origin. The mayor's positive response paved the way for institutionalization of an extensive system of visits and formal relationships with other cities around the world, with the purpose of raising funds for the city and forming friendship ties between Nahariya and various cities around the world (from the website of the Nahariya Municipality: http://www.nahariya.muni.il/nahariyacity/nahariyainfo/Pages/twin\%20Cities.aspx).

Similarly, Beer Sheva too has mutual relations with 12 cities around the world, two in Germany and the rest in the US, France, Canada, Australia, Argentina, Ethiopia, Turkey, Romania, and Yugoslavia. The first alliances within the Twin Cities program were formed with Germany and France, followed by alliances with other cities around the world. The Twin Cities program in Beer Sheva was aimed at encouraging international collaborations, visits of delegations from different cities, and receiving investments and donations for developing the city. Within the program, special emphasis is given to representing Beer Sheva as an international center of knowledge and a young, dynamic, and tolerant city that is the location of impressive integration of immigrants from 63 countries around the world (from the website of the Beer Sheva Municipality: http://www.beer-sheva.muni.il/City/OnTheCity/foreignRelations/Pages/ArimTeomot.aspx).

\section{The Twin Cities Program and Its Contribution to the Feeling of Belonging to Jewish Identity}

The topic of twin cities is encouraged around the world and it has many motives, mainly economic, such as commerce and tourism. In this study, we focused on the ethical aspect of the topic, which is that of national identity, and in the case of Israel-the Jewish-Israeli aspect.

The term Jewish identity refers to questions such as "Who am I?" and "To whom do I belong?" that arise in the process of one's psychological development. In an attempt to answer these and other questions, the individual holds a dialogue with his or her surroundings, including confrontations and comparisons, in order to examine one's belonging on one hand and to characterize the individual's uniqueness on the other. This process reaches its conclusion when integration of all one's sub-identities is achieved, including the ethnic national identity (Laron and Mittelberg 2013).

The term ethnicity originates from the ancient Greek word ethnos, meaning people, i.e., a community of people with common homogeneous origins, history, faith, language, or culture, who live and operate together to achieve common goals (Shenhav n.d.). Therefore, the term ethnic identity includes the following components: self-identity as a member of a group, feeling of belonging and commitment to the group, as well as a sense of differentiation from other groups, positive (or negative) attitudes towards the group, common attitudes, common values, and common ethnic components such as language, behavior, and customs (London and Frank 1987).

Jewish identity, unlike Israeli identity, is a feeling of shared fate and it is comprised of four components: Jewish faith, the Holocaust, the State of Israel, and Zionism. While most people with a Jewish identity are distinguished from each other in their degree of religiosity and Zionism, the Holocaust has become the most dominant component in the Jewish identity of teens and adults in Israel and the Diaspora (Oron 2010) and it serves as the widest common denominator of Jewish belonging at present (Zaban 2007). In fact, the memory of 
the Holocaust has been found to be one of the major factors enhancing the Jewish character of Jewish communities in general and in Israel in particular (Laron and Mittelberg 2013).

In other words, Jewish identity, whether due to descendancy from Jewish parents or from acceptance of Judaism and its practices, means identification with the past, present, and future of the Jewish people and the choice to be a member of the Jewish community and to live a life of which Judaism is a meaningful component (Zaban 2007).

Since belonging to Jewish identity is a matter of choice, researchers have attempted to investigate the Jewish identity of Jews living in Israel. Their endeavors showed that the Jewish-Israeli population has a strong Jewish identity that preserves an affiliation with Jewish tradition and a desire to maintain it, side by side with expectations for full exercising of freedom of choice (Levy, Levinson, and Katz 2002). In this context, a distinction between religious and secular Judaism is in order, where the latter is the object of the current study. Secular Judaism represents an independent humanistic worldview based on values of tolerance and pluralism, and those affiliated with it undertake to preserve the Jewish culture and symbols but reject the obligatory system of decrees that derives from them (Zaban 2007).

However, the attitude of the Jewish-Israeli population to Diaspora Jews is distanced and instrumental. Adult Israelis relate to the Israel-Diaspora relationship as a one-way road, intended first and foremost to serve the needs of Israel. They contend that the relationship with Diaspora Jewry is important for Israel's existence and well-being, and that Jewish education in the Diaspora should serve as a tool for encouraging immigration to Israel and strengthening Zionist ties to Israel (Geokartografia 2010, in Laron and Mittelberg 2013). For example, a survey held in June 2012 found that $80 \%$ of the respondents supported the funding of visits to Israel for young Jews from the Diaspora, but only half of them were willing to provide financial aid to Jewish communities in the Diaspora in times of crisis. Similarly, most of the respondents stated that encouraging immigration is Israel's best response to pervasive global anti-Semitism (B'nai B'rith World Center, 2012). Since one of the goals of the Twin Cities program is, as stated, to strengthen the relationship between the communities, it may be assumed that the program has a significant contribution to reinforcing the sense of identity of residents in both cities involved in the alliance.

Moreover, promoting the cultivation of interpersonal relations between Jews in the Diaspora and Israel is called Jewish peoplehood. The term Jewish peoplehood refers to the sense of Jewish fraternity that lets individuals feel part of a wide Jewish sphere, beyond their personal and communal identity. In other words, Jewish peoplehood means strengthening the sense of the Jewish collective, i.e., strong group cohesiveness and a feeling of mutual responsibility that exceeds geographical boundaries (Hacohen, Wolf, and Horenchik 2014). The research literature indicates that, among other things, the Twin Cities program contributes to this feeling (Ogawa 2012).

In 1990, a partnership agreement was signed between Tiberias and Tulsa, US, in order to strengthen the relationship between the Jewish community of Tulsa and Israel. The relationship between the two cities was first formed during the neighborhood rehabilitation project in Israel but reached a level of formal twinning when the Jewish community in Tulsa increased its involvement in community, educational, and social projects. The deep connections formed between the two cities were manifested in extensive mutual activities, from mutual teen delegations, through business meetings and encounters between educators, to participation in an international tournament in Tulsa (from the website of the Tiberias municipality: https://www.tiberias.muni.il/twin-cities). 
Similarly, in 2004, a Twin cities alliance was formed between Nahariya and New Jersey, with the purpose of strengthening the ties between the Jewish community of New Jersey and Israel. These bonds were aimed at improving the quality of life in the area, with regard to education, society, employment, business, and more, by developing joint work plans between professionals, student exchanges, and active involvement in Israel's development, and preserving secular Jewish identity (from the website of the Jewish Agency: http://www.jewishagency.org/he/partnership2gether-regions/program/5460).

Furthermore, about a year ago, a collaboration agreement was signed between the City of Beer Sheva and Lyons, its sister city since 1977, anticipated to strengthen the sense of Jewish identity in both cities. The city of Lyons has a flourishing Jewish community numbering 35,000, served by over 30 synagogues throughout the city (Beller 2016). In light of the fact that the friendship ties between the two cities have considerably grown over the years, based on a variety of joint activities such as youth delegations, student exchanges, etc. (from the website of the City of Beer Sheva: http://www.beer-sheva.muni.il/City/OnTheCity/foreignRelations/Pages/ArimTeomot.aspx), it may be assumed that the collaboration agreement was signed in order to connect the city of Beer Sheva to other leading cities in the world and in order to enhance the sense of Jewish identity among its residents.

Indeed, in 2009, in a policy proposal to the Government of Israel on strengthening Jewish identity and enhancing the ties between young Jews in Israel and in the Diaspora, the need to preserve a comprehensive and deep relationship between Israel and Diaspora communities was stressed. Such a relationship is dependent on vigorous and continuous interventions between Israel and Jewish communities in the Diaspora, based on collaborations, reciprocity, student exchanges, and more. Cultural bonds between Israel and Jewish communities in the Diaspora, such as those that take place within the Twin Cities program, was only one of a list of recommendations proposed to the government (Kraus 2009).

Further to the above information concerning the goals of the Twin Cities program, the program also appears to contribute to shaping collective Jewish identity in the world in general and in Israel in particular, for which it is proving significant. The current study will try to examine this claim, as stated, through a case study of the Twin Cities program in Beer Sheva and Nahariya and by examining the feeling of belonging to Jewish identity among residents of these cities.

\section{The Connection between Jewish Identity, Feeling of Belonging, and the Twin Cities Program}

The term belonging comes from the field of family studies and refers to a good and positive feeling, where the individual feels that he or she has a place in the family, is wanted, loved, accepted, and is an essential part. Feeling of belonging derives from the basic need to belong and is a motivating force in life, which one strives to realize through his or her behaviors. The expression "I belong therefore I am," coined by the Adlerian school, illustrates this contention (Gutman 2009).

As a rule, belonging refers to the individual's sensation of being part of something big, deep, and significant, and creates a sense of identity and identification. In other words, belonging is the foundation that underlies one's sense of identity. In fact, from the moment of birth a person belongs to something: a family, a society, a culture, or a religion, and on this basis his or her feeling of belonging is formed through empathy, interest, sympathy, equanimity, support, communication, mutual respect, attention, identification, and more (Abramson 2005). 
In addition, it is customary to distinguish between territorial social belonging and cultural belonging. While territorial belonging is strongly related to a specific place, through which a sense of loyalty, solidarity, and community is formed, cultural belonging is characterized by individuals who share a certain set of values that are in consensus although not necessarily arousing conformity (Pollini 2005). Hence, and in light of the fact that in the current study Israel will serve as a case study for examining the contribution of the Twin Cities program to residents' feeling of belonging, it is not inevitable that in Israel it may be possible to distinguish between Israeli identity, deriving from territorial belonging, and Jewish identity, which is an outcome of cultural belonging.

Furthermore, based on the claim that the Twin Cities program reinforces one's sense of Jewish peoplehood, i.e., one's sense of collective identity (Ogawa 2012), it is reasonable to assume that the program will enhance the sense of cultural belonging rather than the sense of territorial belonging: meaning Jewish identity and Israeli identity, respectively.

In this context, it is notable that, in the past, the sense of territorial belonging was stronger than the sense of cultural and family belonging, as individuals usually gave preference to the national good over their personal good. However, in recent decades, Israeli society has been undergoing rapid individuation processes and these are changing the identity hierarchy of the population and affecting people's feeling of belonging to the collectives with which they are affiliated. Thus, at present, the strongest identity is the family identity, followed by Jewish identity and Israeli identity. In other words, the sense of cultural belonging is currently stronger than the sense of territorial social belonging (Zaban 2007). Thus, an inter-generational difference will probably be found in the feeling of belonging to Jewish identity, and this difference too will be examined in the current study.

\section{Research Questions}

The current study will deal with the feeling of belonging to Jewish identity among residents of cities participating in the Twin Cities program chosen as a case study for the current study: Beer Sheva and Nahariya. In other words, the current study will deal with the following questions:

(1) In what way does the Twin Cities program affect Beer Sheva and Nahariya residents' feeling of belonging to Jewish identity?

(2) Do older (over 20) and younger people (under 20) have a different feeling of belonging?

(3) Do residents of Beer Sheva differ from residents of Nahariya in their feeling of belonging?

\section{Research Hypotheses}

Further to the research questions, and as an outcome of the previously presented rationale, three research hypotheses were formulated, each derived from its matching research question:

(1) A difference will be found in the feeling of belonging to Jewish identity between residents of Beer Sheva and Nahariya familiar with the Twin Cities program and those who are not familiar with the program, with the former reporting a stronger feeling of belonging.

(2) The variance in the variable of feeling of belonging to Jewish identity will be explained by age and town of residence, such that older respondents in both cities will report a stronger feeling of belonging than younger respondents. 
(3) A difference will be found in the feeling of belonging between residents of Beer Sheva and residents of Nahariya.

\section{Research Population}

The study included 154 participants with an age range of 17-64. Seven respondents were excluded from the study due to their young age (14-15) and therefore the analysis of findings was based on a sample of only 147 respondents, 52 men and 95 women. Eighty respondents were residents of Beer Sheva and 67 residents of Nahariya. Seventy-eight respondents were familiar with the Twin Cities program, while 69 had never heard of the program. The demographics of the respondents are presented in Table 1. The research participants were located through convenience sampling on the Facebook social network, in a snowball sampling method. Participation in the study was voluntary and the respondents received no compensation.

Table 1

Demographics of the Sample

\begin{tabular}{lllll}
\hline & $\mathrm{N}$ & Mean & Standard deviation & Range \\
\hline Age & 154 & 29.4 & 10.9 & $17-64$ \\
Duration of residency & 147 & 23.26 & 13.01 & $1-60$ \\
\hline
\end{tabular}

\section{Tools}

The respondents were required to complete a unique questionnaire composed for the current study, with the purpose of examining the effect of the Twin Cities program on the feeling of belonging to Jewish identity from a quantitative perspective. The questionnaire was based on the existing research literature on twin cities and was designed in the spirit of the Jewish identity questionnaire developed by Cohen et al. (2008) with the purpose of examining the identity and values of Israeli public high school students.

The questionnaire is divided in three: (1) In the first part, the respondents were requested to complete a short sociodemographic questionnaire in which they were required to state their gender, age, town of residence, religiosity, and marital status. In addition, they were asked to report their country of birth and to declare for how long they had been living in the city. (2) In the second part, the respondents were presented with 22 statements referring to the Twin Cities program and to their feeling of belonging to Jewish identity. The respondents were asked to mark their degree of agreement with each statement on a scale of 1 ("strongly agree") to 4 ("strongly disagree"). (3) In the third part, the respondents were asked to freely answer designated questions related to the Twin Cities program. These questions were intended to examine the respondents' familiarity with the program and their degree of involvement in it.

Because this is a unique questionnaire constructed for the current study, its psychometric features were examined and it was found to be reliable and valid. Reliability calculations of the questionnaire's quantitative part produced a high reliability of $\alpha=.90$.

Moreover, and to lend support to the results of the quantitative questionnaire, a short interview was held with Ms. Mila Zaguri, a representative of the delegations of the Amal High School in Nahariya. The interview was intended to illustrate and validate the quantitative questionnaire and it was comprised of seven questions, three of them related to the motivation of municipalities to form mutual alliances and the others intended to examine the degree of belonging produced by these alliances. 


\section{Procedure}

The questionnaires were distributed online on the Facebook social network and by e-mail, such that each participant completed the questionnaire independently at home on his or her personal computer. Before completing the questionnaire, respondents were informed that the study intends to explore the feeling of belonging among residents of Nahariya and Beer Sheva who are part of the Twin Cities program, and their anonymity was assured. After running the study and before the data analysis, a prescheduled interview was held with Ms. Zaguri.

\section{Data Analysis}

The data were analyzed with the SPSS 20 software, according to the research questions. In order to examine the first research hypothesis, a t-test for independent samples was held, where the dependent variable was the feeling of belonging to Jewish identity and the independent variable was familiarity with the Twin Cities program. Furthermore, and in order to explore the second research hypothesis, a single variable two-way analysis of variance was held with a 2 (residence: Nahariyaor Beer Sheva) $\times 2$ (age: younger or older) design, with the dependent variable being feeling of belonging to Jewish identity. Finally, in order to explore the third research hypothesis, a t-test for independent samples was held, with the dependent variable being the feeling of belonging to Jewish identity.

\section{Results}

The correlations calculated between all the research measures are presented in Table 2. Specific analyses examining the research hypotheses will be presented below.

Table 2

Pearson Correlations between All the Research Measures

\begin{tabular}{llllll}
\hline & Age & Town of residence & Duration of residency & Mean of belonging & Religiosity \\
\hline Age & 1 & $-.193^{*}$ & $.593^{* *}$ & -.116 & .057 \\
Town of residence & & 1 & $-.223^{* *}$ & -.122 & $-.228^{* *}$ \\
Duration of residency & & & 1 & $=.122$ & $.318^{* *}$ \\
Mean of belonging & & & 1 & $=.197^{*}$ \\
Religiosity & & & & 1 \\
\hline $\boldsymbol{*}<<.05 \quad * * .01$. & & & &
\end{tabular}

As evident from Table 2 and contrary to expectations, no correlation was found between the variable mean of belonging and any of the research measures explored, including age, town of residence, and duration of residency. When the variable of religiosity was entered in the model, such that value 1 denoted "secular" and value 2 denoted respondents with some affiliation with religion ("traditional," "religious," or "ultra-Orthodox"), a negative correlation was found between feeling of belonging to Jewish identity and religiosity. Namely, respondents with an affiliation with religion displayed a weaker feeling of belonging than "secular" respondents. Moreover, in order to enter the variable town of residence in the quantitative analysis, its values were converted, such that "Nahariya" received the value 1 while "Beer Sheva" received the value 2. Hence, Table 2 shows that the respondents from Nahariya were older than the respondents from Beer Sheva and that Nahariya had a higher concentration of respondents with a religious affiliation. 


\section{Examination of Hypotheses}

(1) In order to examine the first research hypothesis, whereby a difference would be found in the feeling of belonging to Jewish identity between residents from Beer Sheva and Nahariya familiar with the Twin Cities program and residents unfamiliar with it, a t-test for independent samples was held. As hypothesized, the analysis showed a significant difference in feeling of belonging to Jewish identity as a function of familiarity with the program, $\mathrm{t}(145)=6.58, \mathrm{p}<.01$, but in the opposite direction. In other words, and in contrast to the hypothesis, respondents familiar with the program reported a weaker feeling of belonging to Jewish identity $(\mathrm{M}=2.19, \mathrm{SD}=.46)$ than respondents not familiar with the Twin Cities program $(\mathrm{M}=2.74, \mathrm{SD}=.56)$.

(2) The second research hypothesis, whereby the variance in the variable of feeling of belonging to Jewish identity would be explained by the variables of age and town of residence, was not examined, as no statistical correlation was found between the variable of feeling of belonging to Jewish identity and any of the research variables examined, with regard to which the said research hypothesis was formulated.

Nonetheless, in light of the fact that the only correlation found between the variable of feeling of belonging to Jewish identity and the research variables was the correlation with the variable of religiosity, and in order to assess the differences in feeling of belonging between secular respondents and respondents with a religious affiliation, a t-test for independent samples was held. The analysis showed a significant difference in the feeling of belonging to Jewish identity by religiosity, $\mathrm{t}(145)=2.42, \mathrm{p}<.05$, such that respondents with a religious affiliation reported a weaker feeling of belonging to Jewish identity $(\mathrm{M}=2.36, \mathrm{SD}=.55)$ than secular respondents $(\mathrm{M}=2.59, \mathrm{SD}=.59)$.

(3) In order to examine the third hypothesis, whereby a difference would be found in the feeling of belonging to Jewish identity between residents of Nahariya and residents of Beer Sheva, a t-test for independent samples was held. The analysis showed no significant difference between the feeling of belonging to Jewish identity among residents of Nahariya and residents of Beer Sheva, $t(152)=1.48, p>.05$, such that it may be concluded that the third research hypothesis was not confirmed.

\section{Findings and Conclusions}

The current study explored the contribution of the Twin Cities program to the feeling of belonging to Jewish identity. The premise underlying the current study was that the Twin Cities program raises the feeling of belonging to Jewish identity and that this feeling can be related to one's town of residence and to one's age group. Specifically, the current study hypothesized that residents of Beer Sheva and of Nahariya would have a different feeling of belonging to Jewish identity, as would older and younger respondents, and that familiarity with the Twin Cities program would affect one's feeling of belonging to Jewish identity.

With regard to the first research hypothesis, the research findings show that the respondents' degree of familiarity with the Twin Cities program indeed affects their degree of belonging, but in an opposite direction to that hypothesized. Namely, respondents familiar with the Twin Cities program were found to have a weaker feeling of belonging than respondents who were completely unfamiliar with the program. This finding contradicts the research literature, which indicates that the Twin Cities program increases one's feeling of belonging to secular Jewish identity (Zaban 2007; Kraus 2009), which derives from sense of cultural belonging.

Further, the Twin Cities program was not only found unrelated to feeling of belonging. The research findings also indicated that among those familiar with the program the feeling of belonging was even lower 
than among those unfamiliar with it. This finding may show that familiarity with the program has the opposite effect, weakening the feeling of belonging. This is a unique finding, incompatible with those of previous studies. The research results may point to a new trend, reinforcing Zaban's (2007) contention that in the past 20 years individuals have become more inclined to give priority to their personal individual good over that of the state and collective, such that the Twin Cities program is no longer perceived as a tool for strengthening relations with the Jewish community rather as a tool for personal promotion. This contention is partially supported by quotations brought below that express a clear conception whereby the Twin Cities program is aimed at economic, social, educational, and political nurturing.

At the same time, the current study cannot explain why respondents who are unfamiliar with the program reported a stronger feeling of belonging. Familiarity with the program might in fact weaken the feeling of belonging as it blurs the sense of uniqueness and thus reduces the feeling of belonging. Assuming that people's priorities have indeed changed and become more individual-centered (Zaban 2007), it is also possible that the program is perceived as a barrier to the individual's personal good, as it inevitably involves investment of resources that may come at the expense of resources invested in one's personal interests. This contention is innovative and is not supported by the research literature, and therefore it merits further examination.

Moreover, this finding may also indicate that mere familiarity with the program is insufficient and that its impact on the degree of belonging is also related to involvement in the program. As can be seen from the respondents' demographics, only 21 of the 78 respondents who said that they were familiar with the program had taken an active part in it. Mere familiarity with the program, particularly when inaccurate and lacking foundation, may not serve the purpose of the program. This claim should be further studied. If this assumption is true, practical conclusions can be reached and each municipality should examine how to integrate its residents more actively in the Twin Cities program or how to market it to them in order to ensure that its purpose of achieving a feeling of belonging will indeed be attained.

In addition, we cite Ms. Zaguri, who said that collaborations between twin cities encourage the tourism industry and constitute a foundation for accepting Jewish tourists from the Diaspora. As she said: "It is certainly often also very intriguing... It's easier, there are lots of collaborations that promote tourism to these cities." In other words, residents familiar with the Twin Cities program display a personal interest in Israel and in their sister city and visit it as an outcome of the consequent personal benefits.

In contrast to the second and third research hypotheses, no correlation was found between feeling of belonging to Jewish identity and town of residence and age group. This finding seems to contradict the existing findings on twin cities, as in contrast to previous findings (Ogawa 2012; Kraus 2009), no correlation was found between the program and residents' feeling of belonging. This finding is compatible with recent studies showing that the feeling of belonging to one's family and close community overcomes the feeling of belonging to the collective (Zaban 2007). Hence, and in light of the fact that the current study examined feeling of belonging to Jewish identity, it is not surprising that no correlation was found between this feeling of belonging and town of residence and age group. Another proof is that the average age in the current student was 29.4, indicating that, on average, respondents were from the younger generation. This finding supports Zaban's (2007) statement that in recent decades Israeli society has been undergoing individuation processes that affect its members' sense of collective belonging, which can explain the current findings.

Furthermore, the only variable found correlated with feeling of belonging in the current study is religiosity. Although no hypotheses were brought with regard to the correlation between religiosity and feeling of 
belonging, the correlation found between the variables raises the need to examine the difference in feeling of belonging to Jewish identity between secular people and those with a religious affiliation. This examination showed a significant difference between the groups and that secular people tend to report a stronger feeling of belonging to Jewish identity than those with a religious affiliation. This is a surprising finding, as it would have been expected that people with a religious affiliation would report a stronger feeling of belonging to Jewish identity, in light of the fact that one of the goals of the Twin Cities program is to create a cultural association between Israel and Jewish communities in the Diaspora (Kraus 2009).

A possible explanation is that the feeling of belonging to Jewish identity is not based on the Jewish faith, rather on a sense of peoplehood, i.e., nurturing interpersonal relations between Jews in the Diaspora and the State of Israel (Hacohen, Wolf, and Horenchik 2014) while maintaining values of tolerance and pluralism and the existence of a secular Judaism (Zaban 2007). Hence, it may be assumed that the Twin Cities program promotes the sense of peoplehood (Ogawa 2012) but does not necessarily promote belonging to the Jewish faith, rather belonging to the secular Jewish identity. This contention is compatible with the research findings.

Moreover, examination of the relationship between Beer Sheva and Nahariya and their twin cities shows that the collaboration between the cities is not based on religious values rather on improving quality of life while maintaining a secular Jewish identity (from the Jewish Agency website: http://www.jewishagency.org/he/partnership2gether-regions/program/5460). In addition, the research literature indicates that the greater the religious affiliation, the more close-knit and circumscribed the group cohesion, with no tolerance for acceptance of others. For example, ultra-Orthodox populations tend to surround themselves with physical and virtual walls, as protection against the external world, and the more extreme the religious faith the higher these walls (Hanani 2008). Thus, it is only logical that among this population the feeling of belonging to the secular Jewish identity, as enhanced by the Twin Cities program, will be weaker than among a secular population that strives to preserve its sense of Jewish identity but rejects the associated religious system (Zaban 2007). The current findings confirm this claim.

In this context, it is notable that when the research respondents described their knowledge of the program, none of them mentioned affiliation with religion, and instead most stated the significance of the program for promoting and developing the twinned cities. For example, one of the respondents described: "In Beer Sheva the Twin Cities program nurtured the city in friendship ties with an emphasis on musical, social, and environmental relationships." Another respondent stated: "A program that manages bonds between countries and creates an interaction between them, based on social relationships" and yet another wrote: "Connecting remote cities and places on the political, geographical, and other spheres." When the respondents stated the contribution of the program to their feeling of belonging to the community, the belonging they mentioned was cultural and not religious, as evident from the following quotes:

We were once told at school that they want to take students to the sister country of our city, because it has to do with the community belonging of the city; connects between cities in Israel and Jewish communities in the Diaspora; it is a program intended to impart knowledge and a feeling of belonging and identification with its sister city; it is a program intended to strengthen local residents' feeling of belonging to the overseas community. (Zaban 2007, 18)

\section{Research Limitations and Recommendations for Further Research}

Side by side with the contribution of the current study to the existing body of knowledge on twin cities, it also has several limitations. First of all, the study was conducted only with residents of Beer Sheva and 
Nahariya and therefore its findings are not generalizable. Proper representation of residents from the entire country and from different cities involved in a Twin Cities program may have produced different results or, alternately, the conclusions may have been essentially different than those derived from the current study. Therefore, it is recommended that further research sample respondents from other cities and compare them or, alternately, compare residents of twin cities with residents of cities who do not participate in the program.

Secondly, the questionnaire used in the current study is a self-report questionnaire, which is prone to bias. This questionnaire is meant to follow attitudes more than behavior and thus may not fully reflect respondents' feelings. Moreover, it is a uniquely designated questionnaire constructed for the current study, and although it was found to be reliable and valid these are initial findings and future studies would do well to continue developing it and confirming its data.

Thirdly, other variables beside the fact that the city has a twin cities alliance may also affect its residents' feeling of belonging, and therefore future studies should examine these possible factors and suggest research designs that will enable the researchers to neutralize or uncover these factors.

Finally, in light of the surprising findings of the current study, the effect of the Twin Cities program on feeling of belonging has clearly changed and further research should explore the change, check possible explanations suggested in the current study, and examine the current contribution of the program to the municipality and its residents.

\section{Conclusion}

The current study examined the contribution of the Twin Cities program to feeling of belonging to Jewish identity by town of residence and age group. The current study also examined the possibility that respondents familiar with the Twin Cities program would report a stronger feeling of belonging to Jewish identity. The research findings show that no correlation was found between feeling of belonging and the research measures explored, including town of residence, age group, and duration of residency. The only variable found correlated with feeling of belonging was religiosity, such that secular respondents reported a stronger feeling of belonging than respondents with a religious affiliation. Moreover, and contrary to the hypotheses, the research findings show that respondents who were not familiar with the program reported a stronger feeling of belonging than those familiar with the Twin Cities program.

This study is a unique study and the conclusions derived from it are the first of their kind. The research findings challenge the existing research knowledge in this field and suggest that the effect of the program on feeling of belonging to Jewish identity is contrary to expectations, raising the claim that actual involvement in the program has a greater effect on feeling of belonging than merely knowing about it.

\section{Works Cited}

Abramson, Z. Family and Spousal Therapy according to Adler. Textbook in the Program for Individual Psychotherapy, Adler Institute. 2005. [Hebrew]

Ballantine, J. How Sister City Partnerships Can Play a New Role in a Global Economy. 2013. $<$ https://cities-today.com/how-sister-city-partnerships-can-play-a-new-role-in-a-global-economy/>.

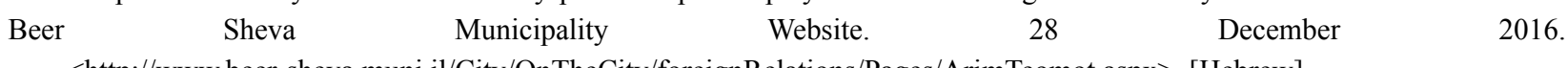

$<$ http://www.beer-sheva.muni.il/City/OnTheCity/foreignRelations/Pages/ArimTeomot.aspx>. [Hebrew] 
Beller, D. "How Do You Say Capital of the Negev in French? Lyons Signed a Partnership Agreement with Beer Sheva." Branza News. 4 April 2017. <http://www.drshabo.branza.co.il/site/article/article_view/news-1481144197>. [Hebrew]

B'nai B'rith World Center. "Seventh Annual Survey of the B'nai B'rith World Center on Attitudes of the Israeli Public towards Diaspora Jewry.” 10 January 2017. <http://www.bnaibrith.org/uploads/7/8/5/9/7859990/diasporasurvey2012_hebrew.pdf>. [Hebrew]

Cohen, A. H., et al. Jewish Identity, Values, and Leisure: The World of Israeli Students in Public High Schools. Tel Aviv: Kalman Center, School of Education, Tel Aviv University, 2008. [Hebrew]

Cremer, R. D., De Bruin, A., and Dupuis, A. "International Sister-Cities: Bridging the Global-Local Divide.” American Journal of Economics and Sociology 60.1 (2001): 377-401.

Federation of Local Authorities in $\quad$ Israel $\quad$ Website. $14 \quad$ January 2017. $<$ http://www.masham.org.il/?CategoryID=221\&ArticleID=94>. [Hebrew]

Grosspietsch, J. "More than Food and Folk Music? Geographical Perspectives on European Town Twinning." Geography Compass 3.3 (2009): 1281-304.

Gutman, D. Alfred Adler-The Meaning of Our Life. Or Yehuda: Dvir, 2009. [Hebrew]

Hanani, H. "Distribution of Israel's Ultra-Orthodox Population." Anashim Yisrael-Hamadrich Lahevra Hayisre'elit. 31 May 2017. <http://www.peopleil.org/details.aspx?itemID=7762>. [Hebrew]

Jayne, M., Hubbard, P., and Bell, D. "Twin Cities: Territorial and Relational Geographies." 2013. $<$ http://journals.sagepub.com/doi/pdf/10.1177/0042098012450480>.

Jewish Agency Website. "The Jewish Agency for Israel." 2 April 2017. $<$ http://www.jewishagency.org/he/partnership2gether-regions/program/5460>. [Hebrew]

Kraus, M. Arevut, Partnership and Responsibility. Policy proposal submitted to the Government of Israel on strengthening Jewish identity and enhancing Israel's ties with young Jews around the world. Jerusalem: The Jewish People Policy Institute, 2009. [Hebrew]

Laron, D. and Mittelberg, D. “'Diaspora Jews Are Our Brethren:’ Issues of Identity and Jewish Peoplehood among Young Israelis.” Iyunim Bechinuch 7.8 (2013): 76-98. [Hebrew]

Levy, S., Levinson, H., and Katz, A. Israeli Jews: A Portrait; Beliefs, Practicing the Tradition, and Values of Jews in Israel 2000. Jerusalem: Gutman Center and the Israel Democracy Institute, 2002. [Hebrew]

London, P. and Frank, N. "Jewish Identity and Jewish Schooling." Journal of Jewish Communal Service 64.1 (1987): 4-13.

Nahariya Muncipality Website. "Naharia-The Web of the City." 28 December 2016. $<$ http://www.nahariya.muni.il/nahariyacity/nahariyainfo/Pages/twin\%20Cities.aspx>. [Hebrew]

Oron, Y. Israeli Identities: Jews and Arabs against One Another. Tel Aviv: Resling, 2010. [Hebrew]

Panka, R. C. "Israel and Youth Exchanges with East Germany's New District States after 1989." Youth Exchanges between Germany and Israel-In Theory and in Practice. Published on the occasion of the 50th Anniversary of German-Israeli Diplomatic Relations and the 60th Anniversary of Youth Exchanges. 2015. [Hebrew]

Pollini, G. "Elements of a Theory of Place Attachment and Socio-territorial Belonging." International Review of Sociology-Revue Internationale de Sociologie 15.3 (2005): 497-515.

Reinstein, Z. "Twin Cities in Israel: Our 'shiduch' with the People of the World." Ynet. 14 January 2017. $<$ http://www.ynet.co.il/articles/0,7340,L-4298743,00.html>. [Hebrew]

Shenhav, Y. $\quad$ "Ethnicity." $\quad 14 \quad$ January 2017. $<$ http://people.socsci.tau.ac.il/mu/yshenhav/files/2013/07/\%D7\%A9\%D7\%A0\%D7\%94\%D7\%91-\%D7\%90\%D7\%AA\%D7 $\%$ A0\%D7\%99\%D7\%95\%D7\%AA.pdf>. [Hebrew]

Sister Cities Website. "Sister Cities International." 13 January 2017. <http://www.sister-cities.org/about-sister-cities-international>. [Hebrew]

Tiberias Municipality Website. "Tiberias-The Web of the City." 15 March 2017. <https://www.tiberias.muni.il/twin-cities>. [Hebrew]

Zaban, H. Belonging and Re-belonging: The Case Study of Inter-marriage between Israeli Jews and Foreigners. MA dissertation. Tel Aviv: Tel Aviv University, 2007. [Hebrew] 